Research Article

\title{
Experimental Research on the Mechanical Performance of the Bolted Rock under Lateral Impact Load: Effect of Prestress, Body Material, and Anchorage Style
}

\author{
Yongzheng Wu $\mathbb{D}^{1,2,3}$ Yukai Fu, ${ }^{1,2,3}$ Denyun Hao, ${ }^{1,2,3}$ and Gangye Guo ${ }^{1,2}$ \\ ${ }^{1}$ CCTEG Coal Mining Research Institute, Beijing 100013, China \\ ${ }^{2}$ Coal Mining and Designing Department, Tiandi Science and Technology Co., Ltd., Beijing 100013, China \\ ${ }^{3}$ State Key Laboratory of Coal Mining and Clean Utilization, Beijing 100013, China
}

Correspondence should be addressed to Yongzheng Wu; tiandiwyz@126.com

Received 5 September 2020; Revised 10 September 2020; Accepted 6 October 2020; Published 26 October 2020

Academic Editor: Guangchao Zhang

Copyright (c) 2020 Yongzheng Wu et al. This is an open access article distributed under the Creative Commons Attribution License, which permits unrestricted use, distribution, and reproduction in any medium, provided the original work is properly cited.

\begin{abstract}
In order to reveal the impact mechanical properties and their key influencing factors of the bolted rock under the lateral impact load, through the lateral drop hammer impact test, the time-history curve of impact force, axial force of the bolt, and surface strain of the sample under different combination types of influencing factors is obtained, and the whole process of deformation and failure of the bolted rock is recorded. The test results show that the material of the bolt has a significant influence on the impact force and axial force of the bolt. There is a positive correlation between bolt strength and impact peak and impact attenuation slope and a negative correlation between bolt strength and impact action time. The effect of prestress on the impact resistance of the bolted rock was also evaluated by the test which suggested that prestress of the bolt can significantly reduce both impact time and bolt axial force of the bolted rock but has limited effect on the impact force. It was also found that the time-history curve of the impact force of anchoring rock mass had significant difference with full-length anchoring and nonanchoring. Compared with the nonanchoring bolt, the full-length anchored rock mass has a larger impact peak and shorter action time, which means that the impact resistance of the full-length bolted rock has a certain degree of weakening. Through scientific research, determining the reasonable bolt material, prestress value, and anchorage style can improve the impact resistance of the sample.
\end{abstract}

\section{Introduction}

With the increase of the intensity and depth of coal mining, accidents due to coal mine rock burst occurred more frequently in China, in recent years. According to incomplete statistics, there are more than one hundred and eighty rock burst mines in China which are mainly distributed in Shandong, Henan, Heilongjiang, and other twenty-five provinces by 2019 [1, 2]. Rock burst will cause roadway collapse, casualties, equipment damage, gas outburst, and other secondary disasters, which have become one of the major disasters that restrict mine safety production seriously [3-5].

Rock burst was a dynamic phenomenon of the sharp brittle failure of the wall rock with giant sonic thrown out of large quantity of rock or coal. In order to solve the problem of rock burst disaster in the mining roadway, microseismic monitoring, acoustic monitoring, electromagnetic monitoring, coal pillar stress, optimizing the layout, crisis relief, and support have been developed to deal with the early warning and prevention of disasters, respectively [6-10]. However, these methods are difficult to be carried out for controlling rock burst effectively because the mechanism, place, and time of rock burst cannot be predicted in advance.

For the roadway support as the last line of defense against rock burst in the mining roadway, a reasonable support scheme was determinated which can effectively reduce the degree of damage to the roadway caused by rock burst, which in turn ensures the safety of life and property in the excavation space. It advocates that the main means of 
defense against rock burst in the mining roadway are highstrength bolt support, U-shaped shed, anti-impact support, etc [11-14]. Compared with other support methods, rock bolting has many advantages, such as convenient construction, preload, and penetrable surrounding rock, which has become the main supporting method of surrounding rock control in the rock burst roadway at present.

Based on the special requirements for support materials in rock burst roadways, experts and scholars from home and abroad have successively developed many new supporting materials, such as high-impact ductile bolt, constant-resistance large deformation bolt, prestressed yield bolt, Garford bolt, Durabar bolt, yielding Secura bolt, and Roofex bolt, which solve the problem of deformation and failure of the rock burst roadway to a certain extent [15-21].

In recent years, the research results of the physical properties of the prestressed bolted rock by experts at home and abroad show that the prestressed bolted rock has a stronger carrying capacity. Prestressed bolted rock is affected not only by static loads but also by dynamic loads frequently in a rock burst roadway, in which failure mechanism and characteristics must be significantly different from those under a single static load [22]. However, the research on the bearing capacity of the prestressed bolted rock is mainly focused on the static load conditions, while little research is focused on the dynamic load conditions in the rock burst roadway for the moment.

It is understood that the prestress, anchoring methods, and material quality of the bolt have an impact on rock bolt support design for the rock burst roadway but that the influence laws of the above supporting parameters on the impact resistance of the bolted rock are not clear yet. In this paper, the lateral drop hammer impact tests of the bolted rock with different materials, different prestress levels, and different anchorage styles are tested by using the drop hammer impact test device to study the dynamic mechanical response laws of the bolted rock under different impact loads, the research results of which can be used to provide test data for the parameter selection of rock bolt support in the rock burst roadway.

\section{Energy Dissipation Mechanism of the Bolted Rock under Impact Load}

When rock burst occurs, the energy generated by rock burst is propagated in the form of stress wave in the surrounding rock, which appears in the form of rock failure, coal cannon, and impact in the roadway facing surface. The dynamic load generated by impact ground pressure can be expressed by the following formula:

$$
\left\{\begin{array}{c}
\sigma_{d P}=\rho C_{P} \nu_{P p} \\
\sigma_{d s}=\rho C_{S} \nu_{S p}
\end{array}\right\},
$$

where $\sigma_{d p}$ and $\sigma_{d s}$ represent the normal and tangential stresses at the source of rock burst, respectively, $\mathrm{Pa}, \rho$ is the density of the medium, $\mathrm{kg} / \mathrm{m}^{3}, C_{p}$ and $C_{s}$ are the propagation velocity of the $P$ wave and $S$ wave in the medium, respectively, $\mathrm{m} / \mathrm{s}$, and $V_{p p}$ and $V_{s p}$ are the particle vibration velocity of the $P$ wave and $S$ wave, respectively, $\mathrm{m} / \mathrm{s}$.

Field measurement shows that the propagation of the stress wave in coal and rock mass is the attenuation law of power function, and the attenuation law of particle vibration velocity can be expressed as

$$
v=v_{0} L^{-\eta}
$$

where $v$ is the peak vibration velocity of the particle at the propagation of the vibration wave, $\mathrm{m} / \mathrm{s}, v_{0}$ is the peak vibration velocity of the particle at the source boundary, $\mathrm{m} / \mathrm{s}, L$ is the distance from the source boundary, $\mathrm{m}$, and $\eta$ is the attenuation coefficient of peak velocity, which is related to the propagation medium.

As shown in Figure 1, the energy dissipation model of the anchor bolt anchorage structure under impact load was established based on the research results of previous scholars [23-25].

It can be seen from Figure 1 that the bolted rock moves instantaneously towards the free space of the roadway after being subjected to the impact load.

Assume that point $C$ on the internal surface of the bolted rock moves to point $C_{1}$ with a displacement of $\Delta r(t)$, and point $B$ at the end of the bolted rock moves to $B_{1}$ with a displacement of $\Delta R(t)$; then, the internal deformation of the bolted rock is $\operatorname{Vr}(t)-V R(t)$. The proximities $\Delta R(t)$ and $\Delta r(t)$ are the function of the impact acting time $t$. Set the working resistance of the bolted rock as $F(t)$, which is mainly related to the mechanical properties of surrounding rocks, the strength of the support system, the prestress, and other relevant parameters.

The energy absorbed by surrounding rocks within the bolted rock mainly consists of two parts: part one is $E_{m 1}$ which is the energy absorbed by the bolted rock moving towards the free space as a whole, and part two is $E_{m 2}$ which is the energy absorbed by the plastic deformation of the bolted rock.

The total energy absorbed by surrounding rocks within the support range can be expressed as follows:

$$
\begin{aligned}
E_{m} & =E_{m 1}+E_{m 2}, \\
E_{m 1} & =\int_{0}^{t} \mathrm{~d} t \int_{0}^{V R(t)} F(t) \mathrm{d} r, \\
E_{m 2} & =\int_{0}^{t} d t \int_{0}^{V r(t)-V R(t)} F^{\prime}(t) \mathrm{d} r .
\end{aligned}
$$

It can be concluded that the total energy absorbed by surrounding rocks within the support range is mainly related to the working resistance of the support system, the instantaneous deformation, and other factors based on the above theoretical analysis. Further analysis shows that the working resistance of the support system is related to the mechanical properties of the support materials, the prestress, and the geological conditions of surrounding rocks.

Therefore, the lateral drop hammer impact tests of the rock mass are carried out for obtaining the effect of the key supporting parameters of the rock burst roadway on the 


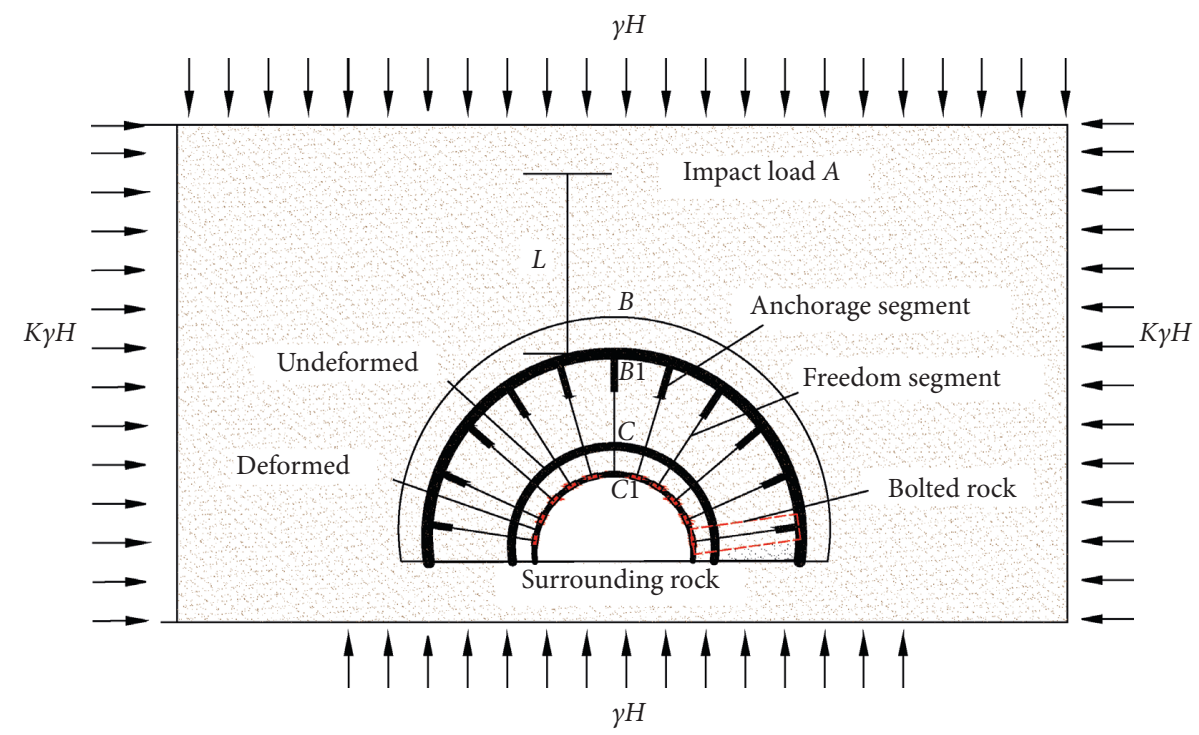

FIGURE 1: Energy dissipation model of the bolted rock under impact load in the roadway.

impact resistance of the bolted rock, such as bolt material, prestress class, and anchorage mode.

\section{The Lateral Drop Hammer Impact Tests of the Bolted Rock}

3.1. Sample Preparation. As can be seen from Figure 2, the rock samples with a size of $150 \mathrm{~mm} \times 150 \mathrm{~mm} \times 1000 \mathrm{~mm}$ were simulated with cement mortar, in which the ratio of cement, sand, and water is $1: 2: 0.5$. The average uniaxial compressive strength of the standard sample was $65 \mathrm{MPa}$ after 28 days of curing. A borehole with a diameter of $20 \mathrm{~mm}$ and a length of $1000 \mathrm{~mm}$ was reserved in the middle lower part of the rock sample for the installation of bolts. The bolts used in the test were left-handed nonlongitudinal ribbed steel bolts, in which reinforcement types were HRB (hotrolled ribbed bar) 400, HRB (hot-rolled ribbed bar) 500, and CRM (crescent ribbed bars) 700, respectively. The bolt length and diameter are $1200 \mathrm{~mm}$ and $10 \mathrm{~mm}$, and the steel tray size is $50 \mathrm{~mm} \times 50 \mathrm{~mm} \times 10 \mathrm{~mm}$.

In order to obtain the mechanical properties of the test bolt, the mechanical properties of HRB500 bolt, HRB500 bolt, and CRM700 bolt with a diameter of $10 \mathrm{~mm}$ were tested, respectively. The test results of the physical properties of the bolt are shown in Table 1 .

It can be seen from the mechanical property test results that the maximum load, yield strength, breaking strength, and elastic modulus of the CRM700 bolt are significantly greater than the other two types of bolts. The impact absorbing energy of HRB400 bolt, HRB500 bolt, and CRM700 bolt is 111,130, and $166 \mathrm{~J}$, respectively, and the impact absorption work of the CRM700 bolt is 1.50 and 1.28 times higher than HRB400 bolt and CRM700 bolt, respectively.

3.2. Experiment Schemes and Design. As shown in Table 2, the experiment scheme is put forward through the orthogonal test method; seventeen models were used to analyze and study the dynamic mechanical response laws of the bolted rock with different materials, different prestress levels, different anchorage styles, and different impact loads, respectively.

3.3. Testing System. The height of the testing machine, effective impact height, maximum impact velocity, and hammer head weight are $13.37 \mathrm{~m}, 12.6 \mathrm{~m}, 15.70 \mathrm{~m} / \mathrm{s}$, and $210.69 \mathrm{~kg}$, respectively, and the overall error of the test system is not more than $2 \%$. The impact force of the hammer head is collected by a force sensor installed in the middle of the hammer head, and the axial force of the bolt is collected by a dynamic force sensor installed at the end of the bolt. The time-history curve of impact force, axial force, and strain of the bolted rock is monitored during the test.

The experiment steps are as follows: firstly, the sample is placed on the support, and the center of the sample is adjusted to align with the hammer head; secondly, the bolt and the sensor are installed; and finally, the data acquisition system is installed and debugged normally. Figure 3 shows the details of the overall spatial arrangement of the test.

\section{Lateral Impact Test Results of the Bolted Rock}

4.1. Deformation and Failure Characteristics. The overall impact failure state of each sample is basically the same, in which fracture failure is radially distributed with the impact point as the center. The fractured bolted rock fractures are mainly shear and tensile fractures. The width of bottom fractures is generally greater than $2 \mathrm{~mm}$ and less than $1 \mathrm{~mm}$ near the impact point. The crack density near the impact point and the crack opening at the bottom are directly proportional to the impact energy, as shown in Figure 4.

It is shown that the prestress, material, and anchorage style of the bolt have large effect on the impact failure of the bolted rock. The impact resistance of the anchor solid is significantly improved with the increase of the strength and 

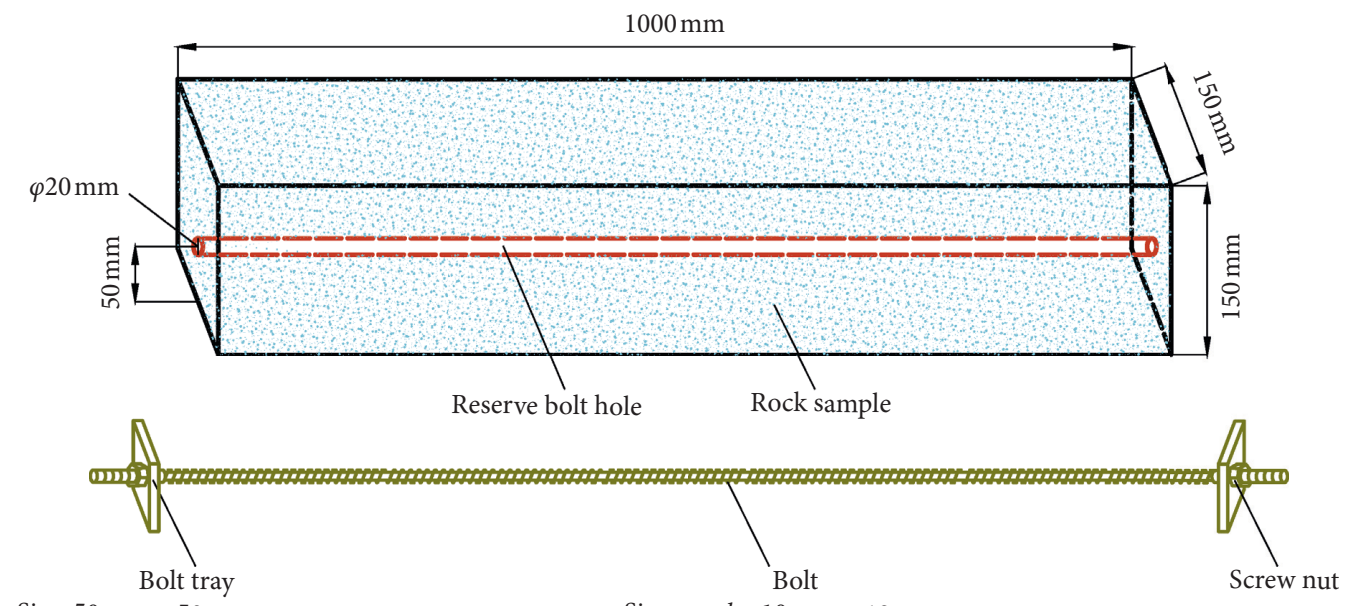

Size: $50 \mathrm{~mm} \times 50 \mathrm{~mm} \times 10 \mathrm{~mm}$

Size: $\varphi \times l=10 \mathrm{~mm} \times 1200 \mathrm{~mm}$

Figure 2: The size of the rock sample and bolt.

TABLE 1: Test results of bolt materials.

\begin{tabular}{|c|c|c|c|c|c|c|c|c|}
\hline \multirow[b]{2}{*}{$\begin{array}{l}\text { Serial } \\
\text { number }\end{array}$} & \multirow[b]{2}{*}{ Bolt type } & \multirow[b]{2}{*}{$\begin{array}{l}\text { Maximum } \\
\text { load }\end{array}$} & \multicolumn{2}{|c|}{ Strength (MPa) } & \multirow[b]{2}{*}{$\begin{array}{c}\text { Elasticity } \\
\text { modulus }(\mathrm{GPa})\end{array}$} & \multirow[b]{2}{*}{$\begin{array}{c}\text { Ultimate } \\
\text { elongation (\%) }\end{array}$} & \multirow[b]{2}{*}{$\begin{array}{l}\text { Reduction of } \\
\text { area (\%) }\end{array}$} & \multirow[b]{2}{*}{$\begin{array}{c}\text { Impact absorbing } \\
\text { energy }(\mathrm{J})\end{array}$} \\
\hline & & & $\begin{array}{c}\text { Yield } \\
\text { strength }\end{array}$ & $\begin{array}{l}\text { Breaking } \\
\text { strength }\end{array}$ & & & & \\
\hline 1 & HRB400 & 43.1 & 378 & 550 & 200 & 28.5 & 65.0 & 111 \\
\hline 2 & HRB500 & 50.2 & 500 & 640 & 200 & 25.5 & 63.0 & 130 \\
\hline 3 & CRM700 & 68.7 & 748 & 876 & 200 & 20.5 & 67.0 & 166 \\
\hline
\end{tabular}

TABLE 2: Experiment scheme and design.

\begin{tabular}{|c|c|c|c|c|}
\hline Sample number & Impact velocity $(\mathrm{m} / \mathrm{s})$ & Impact energy $(\mathrm{J})$ & $P_{s}(\mathrm{kN})$ & $P_{d}(\mathrm{kN})$ \\
\hline M400-0-0-1000 & 3.08 & 1000 & 25.79 & 16.24 \\
\hline M400-0-0-2000 & 4.36 & 2000 & 22.97 & 20.83 \\
\hline M400-0-0-3000 & 5.34 & 3000 & 20.14 & 22.24 \\
\hline M500-0-0-1000 & 3.08 & 1000 & 24.45 & 20.45 \\
\hline M500-0-0-2000 & 4.36 & 2000 & 25.79 & 21.53 \\
\hline M500-0-0-3000 & 5.34 & 3000 & 31.53 & 31.12 \\
\hline M700-0-0-1000 & 3.08 & 1000 & 31.52 & 38.31 \\
\hline M700-0-0-2000 & 4.36 & 2000 & 33.02 & 45.65 \\
\hline M700-0-0-3000 & 5.34 & 3000 & 30.87 & 28.18 \\
\hline M500-0-15-2000 & 4.36 & 2000 & 23.13 & 31.71 \\
\hline M500-0-25-2000 & 4.36 & 2000 & 23.10 & 20.97 \\
\hline M500-0-35-2000 & 4.36 & 2000 & 23.15 & 18.06 \\
\hline M500-0-45-2000 & 4.36 & 2000 & 22.46 & 15.84 \\
\hline M400-1-0-2000 & 4.36 & 2000 & 71.80 & - \\
\hline M400-1-0-3000 & 5.34 & 2000 & 77.40 & - \\
\hline M500-1-0-2000 & 4.36 & 2000 & 83.60 & - \\
\hline M500-1-0-3000 & 5.34 & 2000 & 93.41 & - \\
\hline
\end{tabular}

The impact velocity $v=\sqrt{2 g h}$, the impact energy is $\mathrm{mgh}, h$ is the height of the hammer head, and the mass of the hammer head is $210.69 \mathrm{~kg} . P s$ and $P_{d}$ are the measured laboratory furniture value of the drop hammer impact force and the peak value of the bolt axial force, respectively. $P_{s}$ is the second peak value under the full-length anchorage style, and the dynamic axial force of the bolt under full-length anchoring is 0.3 . M400-0-0-1000 means that the bolt is HRB400, the first 0 means no anchoring, 1 means full-length anchoring, the second 0 means prestress value, and 1000 means impact energy.

toughness of the bolt, which manifested that the number and opening of penetration cracks of the bolted rock are reduced significantly. The bending moment of the bolt rock increases with the increase of bolt prestress and so does the number of nonpenetrating cracks. However, when the bolt prestress exceeds the yield strength of the bolt, the bolt rock will be broken under low impact energy. It is anchorage style that can influence the impact resistance performance of the bolt rock to some extent. When the bolt and rock mass are not anchored, the rock mass with anchor has better impact resistance, and the number of fractures is relatively reduced. The anchor solid is easy to fracture and fail under the 


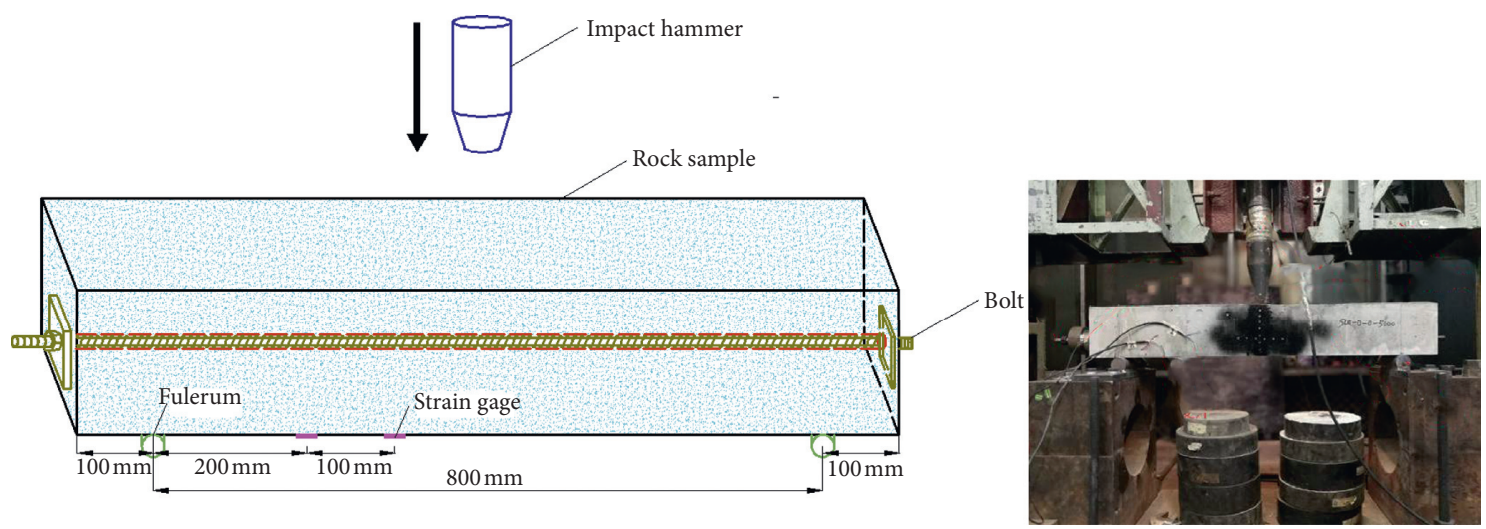

FIgURE 3: Schematic and physical drawings of the overall spatial arrangement of the test.

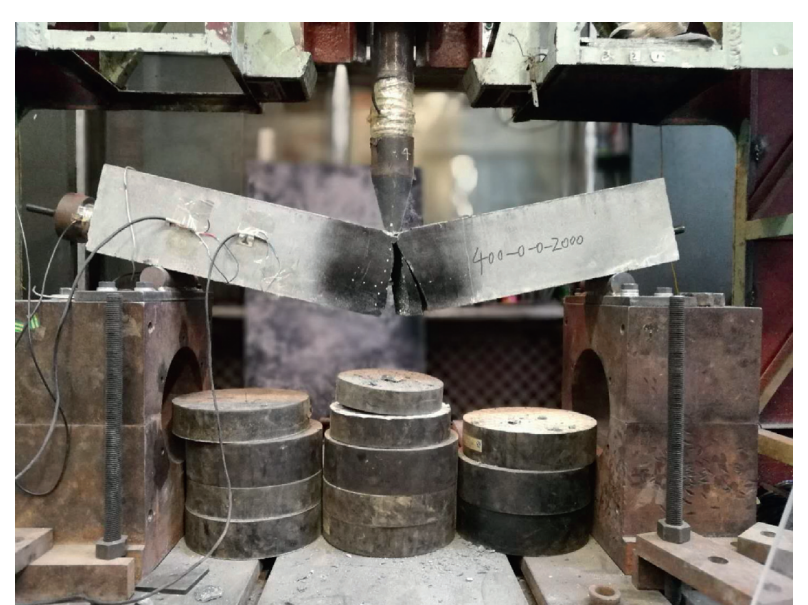

FIgURE 4: Typical deformation and failure characteristics of samples under impact load.

condition of full-length anchoring of the bolt and rock mass. The bending degree of the bolt rock decreases obviously, and a large number of dense fractures appear at the rock impact after the failure.

4.2. The Impact Force-Time History Curves of Different Material Bolts. The time-history curves of bolted rock impact force under different strength bolts and prestress levels are obtained by the experimental results, as shown in Figure 5.

The following conclusions can be drawn from Figure 5:

(1) The time-history curve of the impact force has two wave peaks within $0-0.005 \mathrm{~s}$, which are mainly positively correlated with the stiffness of the contact surface of rock mass and the falling hammer head. The curve in this period reflects the mechanical interaction between the falling hammer and the rock mass, which have little significance to analyze the dynamic mechanical properties of the bolted rock.

(2) The time-history curves of the impact force of the bolted rock of three types of strength bolts are basically the same. With the increase of the impact velocity, the peak value of the impact force of the samples increases with different amplitudes. When the impact energy is constant, the peak value of the impact force increases with the increase of bolt strength.

(3) The impact time has obvious difference before and after the bolt broke; the action time of the impact force increases with the increase of impact velocity before the bolt broke and decreases sharply after the bolt broke. The impact force action time of sample M400 is obviously greater than that of sample M500. The impact effect time of sample M400 is obviously greater than that of sample M500. All CRM700 test bolts are not broken indicating that sample CRM700 has the strongest impact resistance. The main reason for this phenomenon is that the CRM700 bolt has high strength and toughness, and its impact peak value and action time are larger, which significantly improves the impact resistance performance of the bolted rock.

(4) Due to the difference of strength and toughness of the three types of bolts, the slope of the impact force is HRB400, HRB500, and CRM700 in order from small to large in the attenuation stage. Due to the relatively low strength and toughness of HRB400 and HRB500 bolts, all HRB400 and HRB500 bolts were broken when the impact energy exceeded $3000 \mathrm{~J}$, resulting in the phenomenon that the impact force fell to 0 quickly. CRM700 bolts showed good impact resistance. The CRM700 bolts of all the bolted rock samples showed good impact resistance without broken bolts, and their impact force attenuated to 0 slowly.

4.3. Time-History Curves of the Axial Force of Different Material Bolts in the Bolted Rock. Time-history curves of the axial force of different material bolts in the bolted rock are shown in Figure 6.

As can be seen from Figure 6,

(1) The axial force curve of three types of bolts is basically the same with an impact energy of $1000 \mathrm{~J}$ in the bolted rock. The axial force of the HRB400 rock 


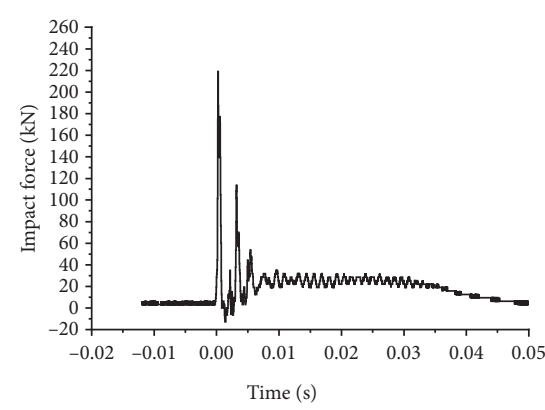

— M400-0-0-1000

(a)

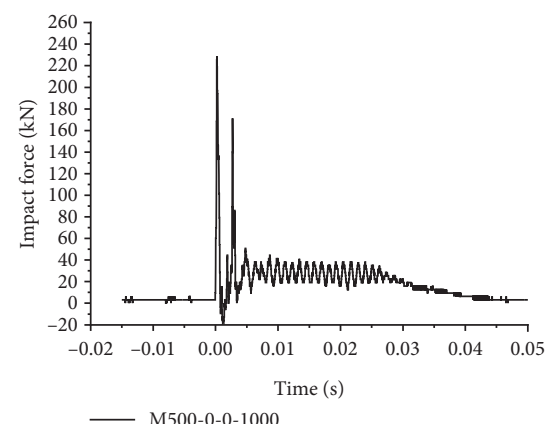

(d)

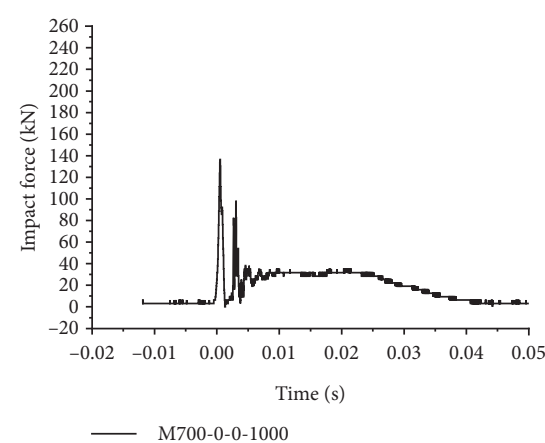

(g)

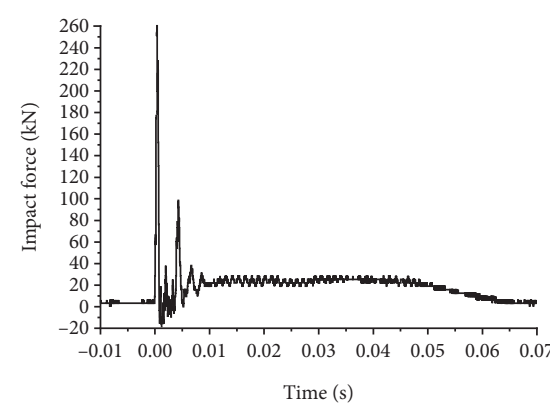

- M400-0-0-2000

(b)

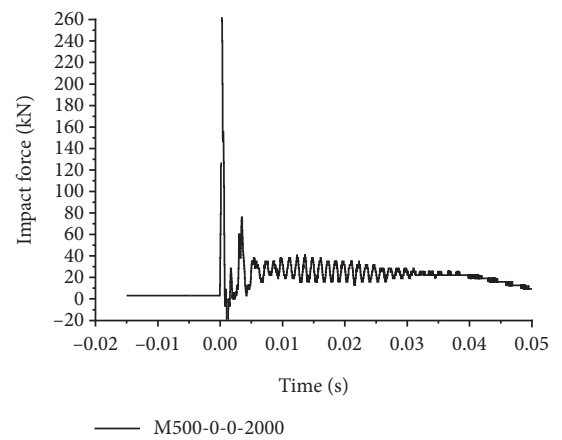

(e)

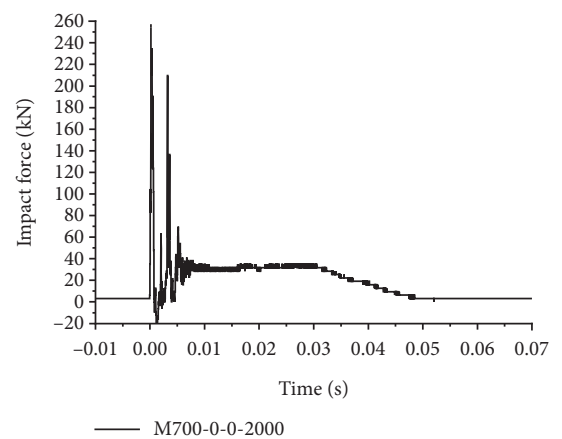

(h)

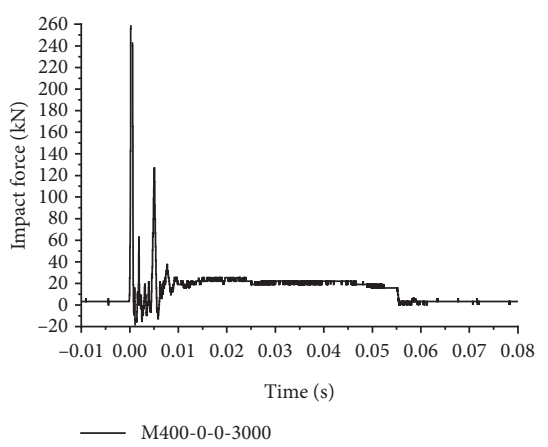

(c)

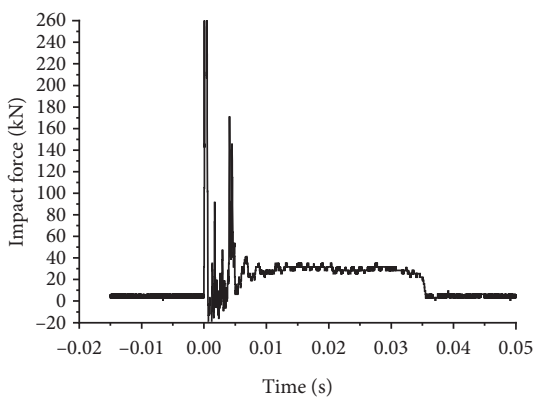

- M500-0-0-3000

(f)

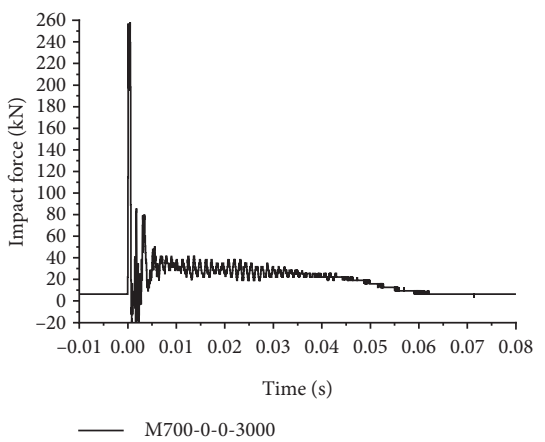

(i)

FIGURE 5: The time-history curves of bolted rock impact force with different strength bolts. (a) M400-0-0-1000. (b) M400-0-0-2000. (c) M400-0-0-3000. (e) M500-0-0-1000. (f) M500-0-0-2000. (g) M500-0-0-3000. (h) M700-0-0-1000. (i) M700-0-0-2000. (j) M700-0-0-3000.

bolt, HRB500 rock bolt, and CRM700 rock bolt is $16.24 \mathrm{kN}, 20.45 \mathrm{kN}$, and $38.31 \mathrm{kN}$, respectively. The axial force peak and action time are positively correlated and negatively correlated with bolt strength, respectively.

(2) The peak axial force of the three kinds of bolts was significantly different with the impact energy $2000 \mathrm{~J}$ in the bolted rock. The axial force of the CRM700 bolt reached $45.65 \mathrm{kN}$, which was significantly higher than that of HRB400 and HRB500 bolts, while the axial force of HRB400 and HRB500 bolts was not significantly different. The axial force action time decreases with the increase of bolt strength, and the axial force action time of the three kinds of bolts shows obvious difference.

(3) HRB400 and HRB500 bolts were broken with the impact energy of $3000 \mathrm{~J}$, and the axial force action time of HRB500, HRB400, and CRM700 bolts was $0.035 \mathrm{~s}, 0.055 \mathrm{~s}$, and $0.066 \mathrm{~s}$, respectively. The peak axial force of the CRM700 bolt is basically the same as that of the HRB500 bolt, which indicates that the high-strength and high-toughness bolt also absorbs energy mainly through deformation under the condition of high impact energy. 


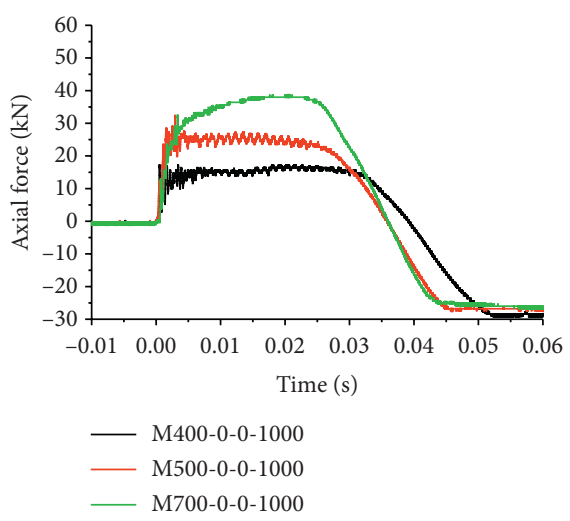

(a)

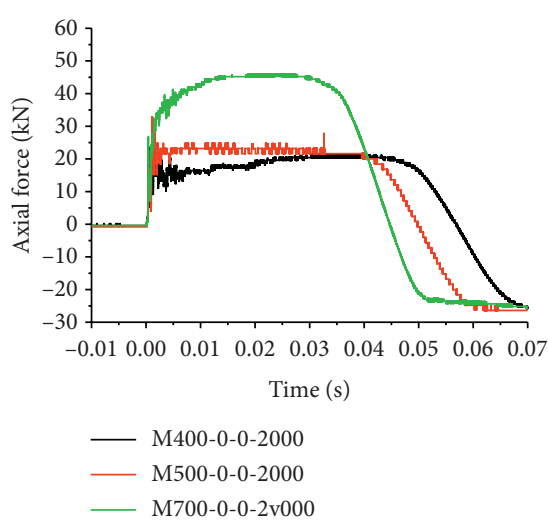

(b)

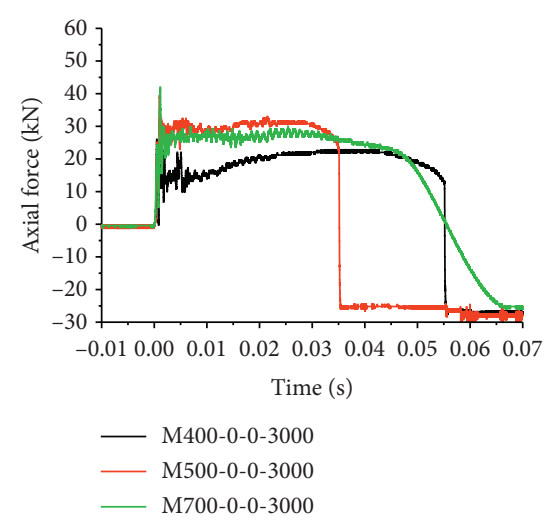

(c)

Figure 6: Time-history curves of the axial force of different material bolts in the bolted rock.

\section{The Impacts of Prestress and Anchorage Style on the Impact Resistance of the Bolted Rock}

5.1. Time-History Curve of Bolted Rock Impact Force under Different Prestresses. Lateral impact tests of the bolted rock with four levels of prestress were carried out for analyzing the influence of prestress on dynamic mechanical properties of the bolted rock. Due to a large number of test data and limited space, only the time-history curve of HRB500 bolted rock impact force is listed as shown in Figure 7.

The following conclusions can be drawn from Figure 7:

(1) The impact force action time decreases from $0.054 \mathrm{~s}$ to $0.025 \mathrm{~s}$ with the increase of bolt prestress from $15 \mathrm{kN}$ to $45 \mathrm{kN}$, and the impact force decreases from $22.47 \mathrm{kN}$ to $21.8 \mathrm{kN}$. The impact force changes little, while the impact force action time changes more significantly.

(2) When the prestress of the bolt is lower than the yield load $39.2 \mathrm{kN}$ of HRB500, the action time and peak value of the impact force of the bolted rock change little, which indicates that the impact resistance of the bolted rock under low-grade prestress has a little change. The whole anchor solid is broken, and the impact force action time is obviously shortened under the prestress of $45 \mathrm{kN}$, which indicates that the impact resistance of the anchor solid is reduced.

(3) The level of prestress has a certain effect on the impact resistance of the bolted rock. The prestress exceeding the yield strength of the bolt will reduce the impact resistance of the bolted rock. This is mainly due to the excessively high prestress which results in the plastic deformation of the bolt, and the plastic deformation capacity under the dynamic load is greatly reduced. This is mainly because the excessive prestress will cause the plastic deformation of the bolt, which will result in the decrease of the plastic deformation capacity under the dynamic load.
5.2. Time History-Strain Curve of the Bolted Rock under Different Prestresses. The strain value on the surface of the bolted rock changes less as the distance from the impact point increases under the action of impact load. Therefore, only the strain-time history curve of the lower surface of the sample at $100 \mathrm{~mm}$ from the impact point is listed in this paper, as shown in Figure 8.

As can be seen from Figure 8,

(1) The positive strain-time history curve belongs to tensile strain, which indicates that the strain on the lower surface of the sample is in the tensile state. The tensile strain is generated due to the fracture of the bolted rock in the time range of $0-0.005 \mathrm{~s}$, which increases sharply and reaches the peak value in a very short time. The tensile strain value drops sharply from the peak after $0.005 \mathrm{~s}$, then increases gradually, and finally decreases slowly. The overall shape of the strain curve is the same as that of the bolt tensile curve, which indicates that the bolt improves the tensile strain state on the surface of the bolted rock, makes the bolt show the dynamic mechanical properties, and thus improves the impact resistance of the samples.

(2) The surface strain of the bolted rock is different with different prestresses. When the prestress increases from $15 \mathrm{kN}$ to $45 \mathrm{kN}$, the strain peak first increases and then decreases and reaches the maximum at $25 \mathrm{kN}$, indicating that reasonable prestress can improve the tensile strain state of the rock surface and the impact resistance of the sample. Excessively low prestress cannot significantly improve the impact resistance of the anchor solid, and excessively high prestress will cause the bolt to be broken easily. Too high prestress has poor effect on improving the strain state of the sample surface.

5.3. Time-History Curves of the Impact Force of the Bolted Rock under Different Anchorage Styles. In order to analyze the 


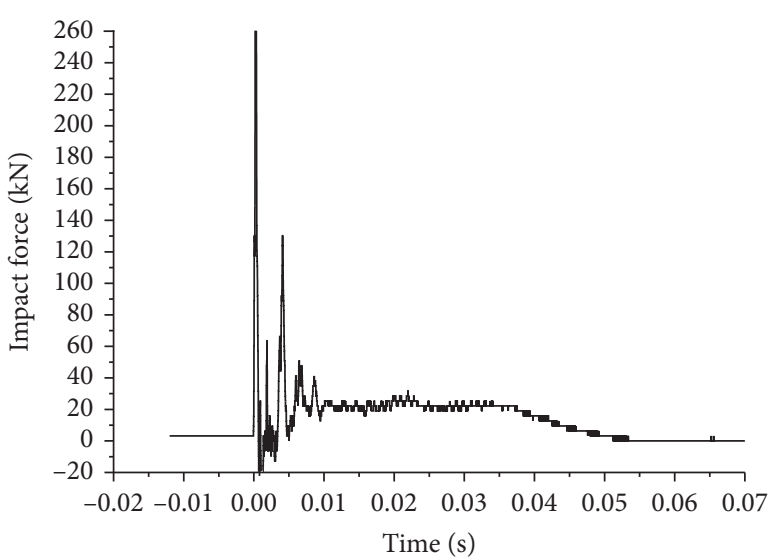

- M500-0-15-2000

(a)

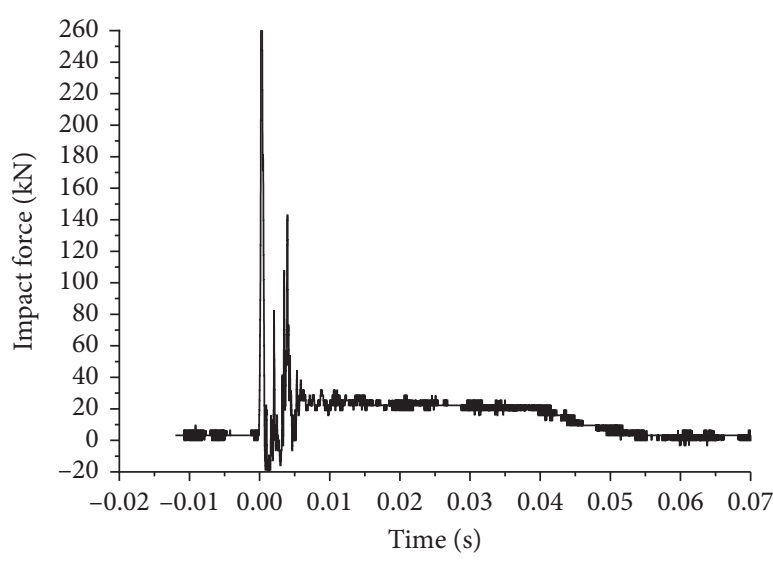

— M500-0-35-2000

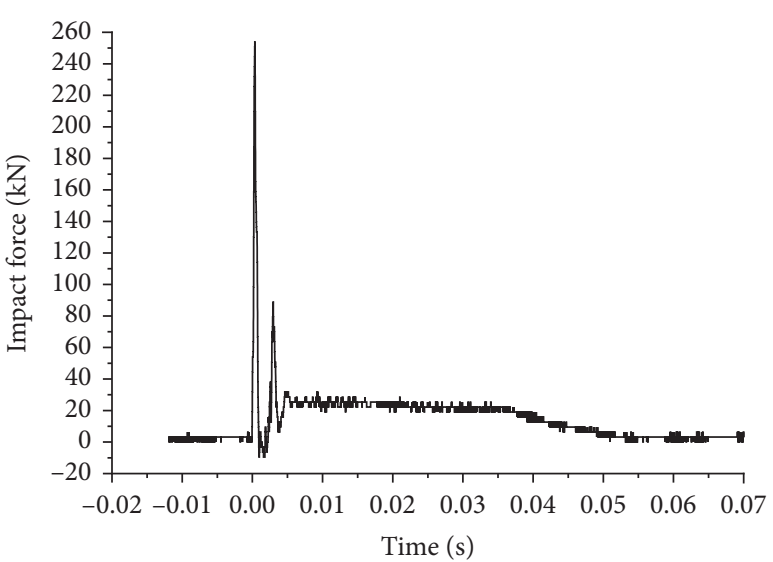

- M500-0-25-2000

(b)

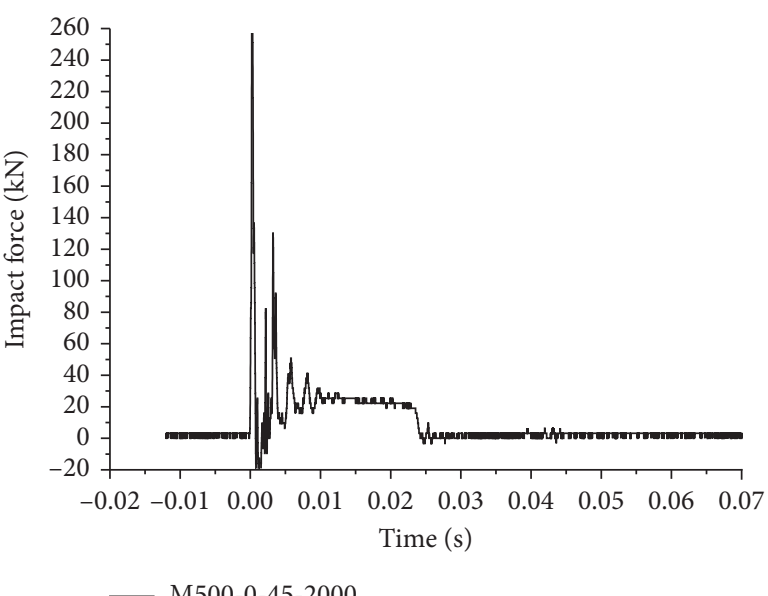

(d)

FIGURE 7: Time-history curves of bolted rock impact force under different prestresses. (a) M500-0-15-2000. (b) M500-0-25-2000. (c) M5000-35-2000. (d) M500-0-45-2000.

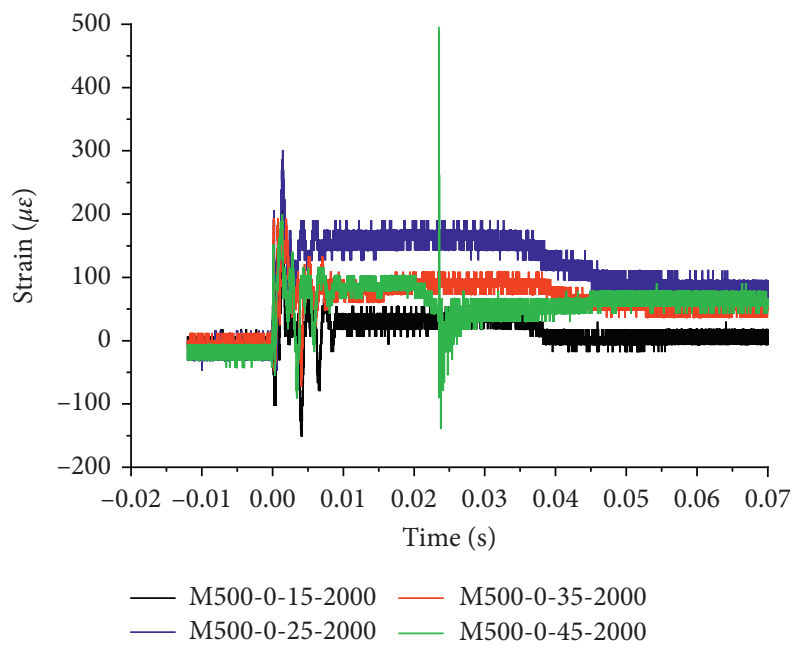

FIGURE 8: Time history-strain curve of the bolted rock under different prestresses. influence of anchorage styles on the dynamic mechanical properties of the bolted rock, impact tests were carried out with two anchorage styles, three types of bolts, and two types of impact energy. The impact-time history curves of the fulllength anchorage of HRB400 and HRB500 bolts are shown in Figure 9. Since the axial force and surface strain of the sample have almost no change under the full-length anchoring mode, the analysis is not carried out here.

The following conclusions can be drawn from the comparison between Figures 4 and 9:

(1) The time-history curve of the impact force under the full-length anchorage style is obviously different from that under the nonanchorage style, which shows the impact force under the full-length anchorage style fluctuates for many times, and the peak value of the impact force decreases gradually. However, the impact curve under the nonanchorage style does not have these characteristics. This is 


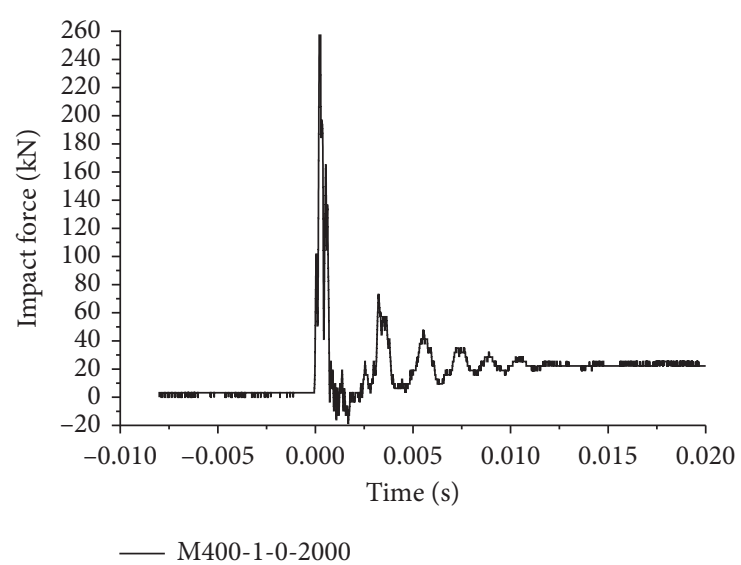

(a)

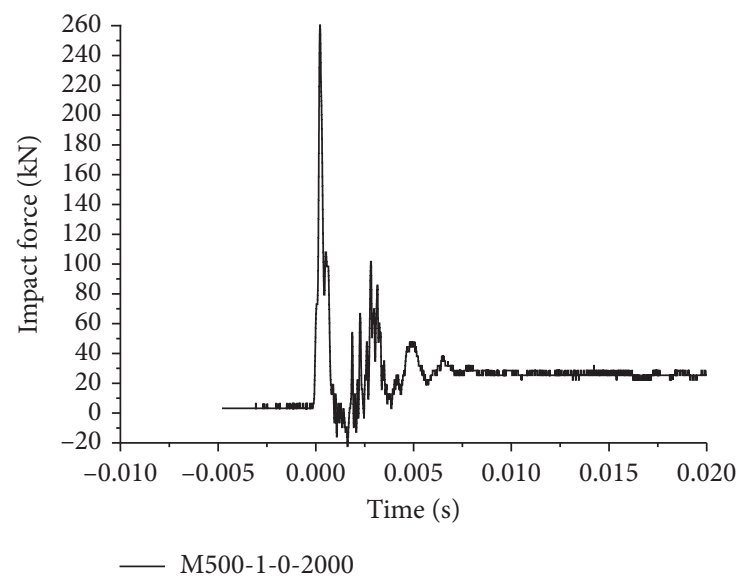

(c)

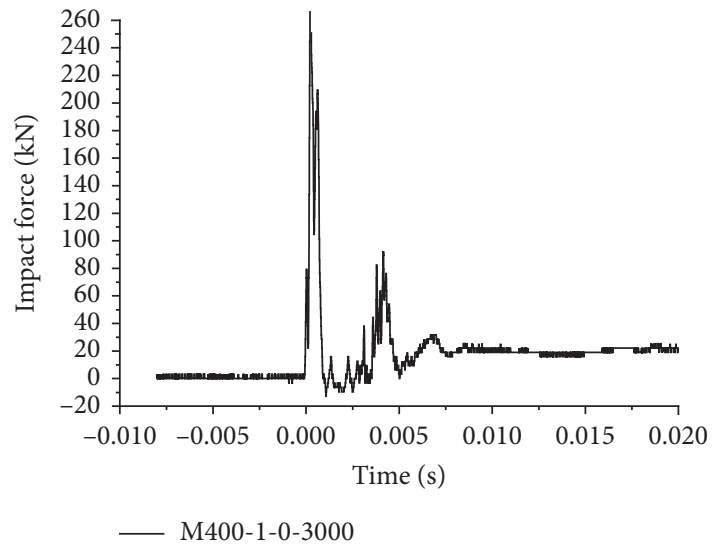

(b)

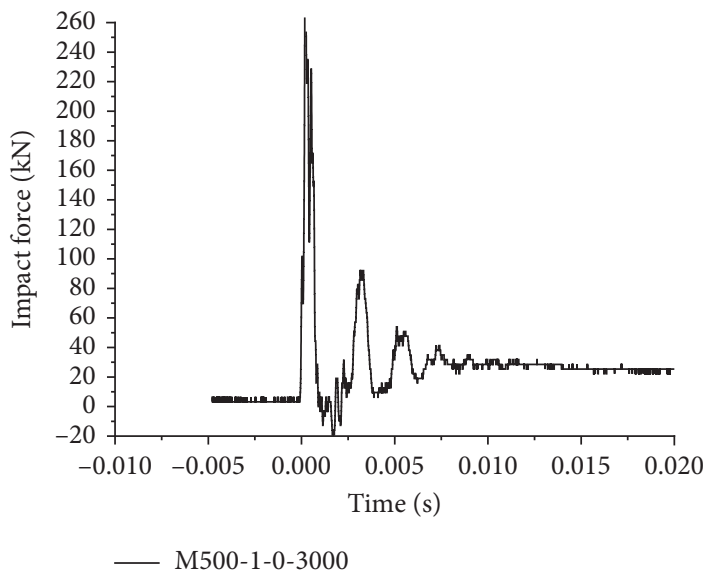

(d)

Figure 9: Time-history curves of the impact force of the bolted rock under different anchorage styles. (a) M400-1-0-2000. (b) M400-1-03000. (c) M500-1-0-2000. (d) M500-1-0-3000.

mainly due to the fact that the full length of the bolt is in the tensile state under the nonanchorage style, the impact force action time is long, and the peak value is small, and the overall impact resistance of the sample is strong. The impact force action time and peak value obviously decrease and increase, respectively, under the full-length anchorage style, which indicates that the overall stiffness of the bolted rock under the full-length anchorage style is increased, but the overall impact resistance performance is reduced to some extent.

(2) The impact peak value increases with the increase of bolt strength and impact energy, that is, the bolt strength can improve the overall stiffness of the sample, and the impact peak value is also larger under impact load. When the impact energy is $2000 \mathrm{~J}$ and $3000 \mathrm{~J}$, the second impact peak value of the bolted rock sample of HRB400 bolt is $71.8 \mathrm{kN}$ and $77.4 \mathrm{kN}$, respectively, while the second impact peak value of the bolted rock sample of HRB500 bolt is $83.6 \mathrm{kN}$ and $93.4 \mathrm{kN}$, respectively.

\section{Conclusions}

The material, prestress, and anchorage style of the bolt play an important role in the impact resistance of the bolted rock that is pivotal to sustainable, safe, and efficient development of coal resources in underground coal mines. The results were based on the analysis of the theoretical and laboratory tests that provide valuable guidance for the selection of supporting materials and the design of supporting parameters in the rock burst roadway. Some conclusions are summarized in the following:

(1) The theoretical analysis shows that the main factors affecting the energy absorption of the surrounding rock within the support range are the prestress, material, and anchorage style of the bolt. At the same time, the theoretical calculation formula of the energy absorption of the surrounding rock within the bolting range is obtained based on the model of energy dissipation of the anchor solid under impact load.

(2) The laboratory tests revealed that the bolt material has a significant influence on the impact force and 
axial force of the bolt, of which strength and toughness can significantly improve the impact resistance of the bolted rock sample. Excessive low or high prestress is not conducive to improving the impact resistance of anchor solids. The reasonable range of prestress should not only improve the tensile strain state of the rock mass surface but also improve its impact resistance. The overall impact resistance of the sample is strong under the nonanchorage style, but the overall impact resistance performance is reduced to some extent under the full-anchorage style.

(3) The research results show that the material, prestress, and anchorage style of the bolt have a certain effect on the impact resistance of the bolted rock. The impact resistance of rock mass can be improved by determining reasonable bolt material, prestress value, and anchorage mode.

\section{Data Availability}

The data used to support the findings of this study are available from the corresponding author upon request.

\section{Conflicts of Interest}

The authors declare that they have no conflicts of interest.

\section{Authors' Contributions}

All the authors contributed extensively to the work. Yongzheng Wu conceived and designed the laboratory tests. Yongzheng $\mathrm{Wu}$ and Yukai Fu contributed to theoretical analysis and analyzed the data. Yukai Fu and Gangye Guo wrote the paper. Gangye Guo modified the manuscript.

\section{Acknowledgments}

This work was financially supported by the National Natural Science Foundation of China (Grant no. 51974160) and the National Natural Science Foundation of China (Grant no. 51804159).

\section{References}

[1] H.-P Kang, Y. Wu, J. He, and Y.-K Fu, "Rock bolting performance and field practice in deep roadway with rock burst," Journal of China Coal Society, vol. 40, no. 10, pp. 2225-2233, 2015, in Chinese.

[2] R. Frith, G. Reed, and A. Jones, "A causation mechanism for coal bursts during roadway development based on the major horizontal stress in coal: very specific structural geology causing a localised loss of effective coal confinement and Newton's second law," International Journal of Mining Science and Technology, vol. 30, no. 1, pp. 39-47, 2020.

[3] Science and Technology Equipment and Department of China Administration of Coal Mine Safety, National Special Investigation Report on Coal Mine Rockburst, Science And Technology Equipment of China Administration of Coal Mine Safety, Beijing, China, 2017.
[4] A. Keith, Heasley, and I. Berk Tulu, "Using la model to analyze coal bumps," International Journal of Mining Science and Technology, vol. 28, pp. 729-737, 2018.

[5] H. Lawson, "Exploration of petrographic, elemental, and material properties of dynamic failure-prone coals," International Journal of Mining Science and Technology, vol. 30, no. 1, pp. 69-75, 2020.

[6] C. Wei, C. Zhang, I. Canbulat, A. Cao, and L. Dou, "Evaluation of current coal burst control techniques and development of a coal burst management framework," Tunnelling and Underground Space Technology, vol. 81, pp. 129-143, 2018.

[7] Q. Liming, L. Zhentang, W. Enyuan, and L. Baolin, "Earlywarning of rock burst in coal mine by low-frequency electromagnetic radiation," Engineering Geology, p. 105755. In press, 2020.

[8] S. Wasilewski, "Gas-dynamic phenomena caused by rock mass tremors and rock bursts," International Journal of Mining Science and Technology, vol. 30, no. 3, pp. 413-420, 2020.

[9] J. Wen, H. Li, F. Jiang, Z. Yu, H. Ma, and X. Yang, "Rock burst risk evaluation based on equivalent surrounding rock strength," International Journal of Mining Science and Technology, vol. 29, no. 4, pp. 571-576, 2019.

[10] X. Zhang, J. Hu, H. Xue et al., "Innovative approach based on roof cutting by energy-gathering blasting for protecting roadways in coal mines," Tunnelling and Underground Space Technology, vol. 99, p. 103387, 2020.

[11] K. Yu, F. Ren, R. Puscasu, P. Lin, and Q. Meng, "Optimization of combined support in soft-rock roadway," Tunnelling and Underground Space Technology, vol. 103, p. 103502, 2020.

[12] Y. Jiang, Y. Zhao, H. Wang, and J. Zhu, "A review of mechanism and prevention technologies of coal bumps in China," Journal of Rock Mechanics and Geotechnical Engineering, vol. 9, no. 1, pp. 180-194, 2017.

[13] Z. Yang, C. Liu, S. Tang, L. Dou, and J. Cao, "Rock burst mechanism analysis in an advanced segment of gob-side entry under different dip angles of the seam and prevention technology," International Journal of Mining Science and Technology, vol. 28, no. 6, pp. 891-899, 2018.

[14] Y. Wu, J. He, and Y. Wang, "Study on failure mechanism and control technology of large cross section rockburst roadway," Coal Science and Technology, vol. 46, no. 1, pp. 61-67, 2018.

[15] Y. Fu, Y. Wu, W. Ju, and J. He, "Response and impact mechanism of rock bolt under lateral dynamic impact load," Journal of China Coal Society, vol. 41, no. 7, pp. 1651-1658, 2016.

[16] M. He and Z. Guo, "Mechanical property and engineering application of anchor bolt with constant resistance and large deformation," Chinese Journal of Rock Mechanics and Engineering, vol. 33, no. 7, pp. 1297-1308, 2014.

[17] B. Zhang, Z. Zhang, B. Wang, and L. Zhou, "Experimental study of application of yielding bolt to large deformation tunnel," Rock and Soil Mechanics, vol. 37, no. 7, pp. 2047-2055, 2016.

[18] R. Varden, R. Lachenicht, J. Player et al., "Development and implementation of the garford dynamic bolt at the Kanowna Belle mine," in Proceedings of the 10th Underground Operators Conference, The Australasian Institute of Mining and Metallurgy, Launceston, Australia, October 2008.

[19] F. Charette and M. Plouffe, "Roofex-results of laboratory testing of a new concept of yieldable tendon," in Proceedings of the 4th International Seminar on Deep and High Stress Mining, pp. 395-404, Australian Centre for Geomechanics, Perth, Australia, November 2007. 
[20] C. C. Li, "A new energy-absorbing bolt for rock support in high stress rock masses," International Journal of Rock Mechanics and Mining Sciences, vol. 47, no. 3, pp. 396-404, 2010.

[21] H. Kang, "Sixty years development and prospects of rock bolting technology for underground coal mine roadways in China," Journal of China University of Mining \& Technology, vol. 45, no. 6, pp. 1071-1081, 2016.

[22] H. Li, H. Jiang, J. Zhao et al., "Some problems about safty analysis of rock engeering under dynamic load," Chinese Journal of Rock Mechanics and Engineering, vol. 22, no. 11, pp. 1887-1891, 2003, in Chinese.

[23] Y. Wu, J. Chen, J. Jiao et al., "Damage and failure mechanism of anchored surrounding rock with impact loading," Journal of China Coal Society, vol. 43, no. 9, pp. 2389-2397, 2018, in Chinese.

[24] Y. Wu, F. Gao, J. Chen et al., "Experimental study on the performance of rock bolts in coal burst-prone mines," Rock Mechanics and Rock Engineering, vol. 52, no. 10, pp. 39593970, 2019.

[25] Y. He, W. Ju, Y. Wu et al., "Study on principle application of energy absorption and bump reduction of high impact toughness rock bolt," Coal Science and Technology, vol. 47, no. 11 , pp. $68-75,2019$, in Chinese. 